\title{
MEDIAÇÃO PENAL E VIOLÊNCIA DE GÊNERO NO BRẢSIL: UMA EXPERIÊNCIA NECESSÁRIA
}

\author{
Celeste Leite Dos SAntos \\ Doutora pela USP \\ Especialista em Direito Penal Econômico \\ pela Universidade de Coimbra \\ Especialista em Interesses Difusos \\ e Coletivos pela CEAF-ESMP \\ Promotora de Justiça, Coordenadora \\ Geral dos Grupos de Estudos \\ dos Membros do MPSP \\ celestesantos454@botmail.com
}

\begin{abstract}
RESUMEN
O presente artigo analisa a questão da revitimização de mulheres vítimas de violência de gênero em razão do desconbecimento dos operadores jurídicos dos aspectos cíveis abrangidos pela Lei n. 11.340, de 7 de agosto de 2006 na sua integralidade. Persiste a separação entre os aspectos criminais, cíveis e emocionais que surgem como consequências pelo crime praticado. A mediação penal constitui importante ferramenta extraprocessual de um Ministério Público Resolutivo, cabendo ainda ao parquet o dever de fornecer orientação jurídica adequada às vítimas de crimes.
\end{abstract}

Palabras clave: mediaçao, violência de gênero, sistema de justiça.

\section{ABSTRACT}

The current article looks into the question of victimism over such women subject to gender violence for a poor knowledge of legal tools of civil aspects penned by Act number 11.3407 August 2006 as a whole. There is still a breach among criminal, civil and emotional areas arising from the crime which has been committed. Penal mediation makes a good off process tool of a Resolute Public Ministry, yet comprising the right to provide with the right legal guidance to victims of crime.

Keywords: mediation, gender violence, system of justice.

\section{ZUSAMMENFASSUNG}

Der vorliegende Artikel untersucht die Re-Viktimisierung der Frauen, die Opfer von geschlechtsspezifischer Gewalt wurden, verursacht durch Unkenntnis der Juristen bezüglich zivilrechtlicher Aspekte, die in ibrer Ganzheit im Gesetz Nr. 11340 vom 7. August 2006 festgebalten sind. Es bestebt weiterbin eine Abspaltung der kriminalistischen, zivilrechtlichen und emotionalen Aspekte, die als Folge des Verbrechens auftreten. Die strafrechtliche Mediation stellt ein wichtiges zusätz- 
liches Prozesswerkzeng im Schlichtungsverfabren der Staatsanwaltschaft dar, wobei noch Handlungsspielraum dahingehend besteht, den Opfern von Straftaten eine angemessene juristische Beratung teil werden zu lassen.

Schlüsselwörter: meditation, geschlechtsspezifische gewalt, justizsystem.

SUMARIO: I. A VIOLÊNCIA DE GÊNERO E O MARCO LEGAL BRASILEIRO DA LEI MARÍA DA PENHA (LEI NÚM. 11.340, DE 7 DE AGOSTO DE 2016).--II. A MEDIAÇÃO PENAL E A JUSTIÇA RESTAURATIVA.--III. CARACTERÍSTICAS DA MEDIAÇÃO PENAL.-1. Objetivos da mediação penal.-2. Objeções à aplicação da mediação penal em contexto de violência doméstica e familiar contra a mulher.-3. Da possibilidade da mediação penal.-IV. CONCLUSÃO.-V. BIBLIOGRAFIA.

\section{A VIOLÊNCIA DE GÊNERO E O MARCO LEGAL BRASILEIRO DA LEI MARÍA DA PENHA (LEI NÚM. 11.340, DE 7 DE AGOSTO DE 2016)}

A Lei Maria da Penha, marco legal no combate à violência doméstica e familiar contra a mulher, já completou mais de uma década sem que tenhamos alcançado sua plena efetividade, ou seja, adoção de políticas públicas eficientes voltada à prevenção, erradicação, bem como repressão dos casos em que haja a prática de violência física, psicológica, sexual, patrimonial e moral (art. 7. ${ }^{\circ}$, incisos I a V da Lei núm. 11.340/2006). Tal marco legal representou avanço, fruto de resposta à condenação do Estado Brasileiro pela Organização dos Estados Americanos, apresentado pela Senhora Maria da Penha (Relatório núm. 54/2001, Caso núm. 12.051).

Houve avanço no ciclo vicioso que vigorava no sistema de justiça brasileiro: a mulher sofria violência no recinto de seu lar, sofria revitimização ao levar o fato ao conhecimento das autoridades policiais (vitimização secundária- por meio de questionamentos inadequados e imputação de culpa do ocorrido à própria vítima) e, novo episódio de vitimização pelo Poder Judiciário (vitimização terciária), seja na esfera penal em que os casos eram arquivados ou os réus absolvidos (frequentemente se arguia que seria a palavra de um contra a palavra de outro), seja ao deduzir sua pretensão perante a Vara de Família (através de alegações de que agia motivada por um desejo de vingança). Assim, a vítima era ouvida por todos os integrantes do sistema de justiça, porém não era escutada.

Atento à necessidade de se obter grau civilizatório que almeje a igualdade efetiva entre homens e mulheres, houve por bem o legislador ordiná- 
rio estabelecer o princípio do juiz do fato nos Juizados Especiais de Violência Doméstica e Familiar contra a mulher, in verbis:

«Art. 13. Ao processo, ao julgamento e à execução das causas civeis e criminais decorrentes da prática de violência doméstica e familiar contra a mulher aplicar-se-ão as normas do Código de Processo Penal e Processo Civil e da legislação específica relativa à criança, ao adolescente e ao idoso que não conflitarem com o estabelecido nesta lei (grifamos)» ${ }^{1}$.

Desse modo, foi reconhecida a necessidade do tratamento integrado dos casos de violência doméstica e familiar não apenas para fins de apuração e prevenção, mas também devido à especialidade do conflito, que a causa seja apreciada pelo promotor de justiça e juiz de direito do fato, buscando não apenas a obtenção da reprimenda penal ao ato praticado, mas sobretudo a prevenção de novos delitos, através da preservação da integridade física, psíquica, moral, patrimonial da mulher, da prole e do próprio agressor.

A díade justiça criminal $\mathrm{x}$ justiça cível remanesce na prática de nossos Tribunais, uma vez que os juízes de direito e promotores de justiça com atribuição para oficiar perante a Vara da Violência Doméstica e Familiar contra a Mulher, via de regra, não apreciam as questões atinentes a guarda, patrimônio do casal, divórcio, limitando-se na grande maioria dos casos à análise da concessão de separação de corpos do casal e restrição de visitas à prole, a título de medida protetiva.

Desse modo, forçoso reconhecer que os juízes e promotores de justiça não aplicam a máxima do juiz e promotor do fato, ignorando a competência cumulativa que lhes foi atribuída, limitando-se a criar programas que ora isolam o agressor (programas educativos ao agressor, adoção de medidas protetivas que obrigam o agressor), ora isolam a mulher (adoção de medidas protetivas à vítima que possuem caráter cautelar, mas não solucionam o conflito), inexistindo um programa único que busque o tratamento do conflito apresentado de forma integrada, por meio de técnicas de gerenciamento adequado que são possíveis em um ambiente de mediação penal. Ambos se sentem penalizados pelo sistema de justiça e nunca acolhidos, entendidos e ainda que ouvidos, escutados. A participação de agressor e vítima, ainda que se adotem medidas visando à humanização do processo, remanesce no nível instrumental, por falta da integração de

${ }^{1}$ Lei núm. 11.340, de 7 de agosto de 2006, disponível em bttp://www.planalto.gov.br/ ccivil_03/_ato2004-2006/2006/lei/l11340.btm (acesso em 17.05.2018). 
medidas que seriam possíveis no ambiente imparcial e de assunção de responsabilidades da mediação penal.

Nessa seara, abre-se espaço para a adoção de programas de mediação penal pré processuais e processuais no âmbito do Ministério Público e do Poder Judiciário, devendo, desde já anotar que em razão da competência cumulativa do Juizado Especial de Violência Doméstica e Familiar Contra a Mulher para processo, julgamento e execução dos crimes decorrentes de violência doméstica e familiar contra a mulher, na fase processual seria a sua disponibilização não apenas recomendável, mas obrigatória ${ }^{2}$ (cfr. art. 334 da Lei núm. 13.105 de 16 de março de 2015 c.c. art. 13 da Lei núm. 11.340/2006).

\section{A MEDIAÇÃO PENAL E A JUSTIÇA RESTAURATIVA}

Knopepfler propugna que o advento da justiça restaurativa está ligado a um certo grau de fracasso em relação ao sistema penal clássico e sua expressão retributiva e reabilitadora ${ }^{3}$. Pela concepção retributiva, a pena

${ }^{2}$ A esse respeito, estabelece o Código de Processo Civil (Lei núm. 13.105, de 16 de março de 2015): «Art. 334. Se a petição inicial preencher os requisitos essenciais e não for o caso de improcedência liminar do pedido, o juiz designará audiência de conciliação ou de mediação com antecedência mínima de 30 (trinta) dias, devendo ser citado o réu com pelo menos 20 (vinte) dias de antecedência. $\$ 1^{\circ} \mathrm{O}$ conciliador ou mediador, onde houver, atuará necessariamente na audiência de conciliação ou de mediação, observando o disposto neste Código, bem como as disposições da lei de organização judiciária. $\mathbb{\$}$ oㅡ Poderá haver mais de uma sessão destinada à conciliação e à mediação, não podendo exceder a 2 (dois) meses da data de realização da primeira sessão, desde que necessárias à composição das partes. $\mathbb{3}$ ?o $\mathrm{A}$ intimação do autor para a audiência será feita na pessoa de seu advogado. $\$ 4^{\circ}$ o A audiência não será realizada: I. se ambas as partes manifestarem, expressamente, desinteresse na composição consensual; II. quando não se admitir a auto composição. $\$ 5 \circ \mathrm{O}$ autor deverá indicar, na petição inicial, seu desinteresse na auto composição, e o réu deverá fazê-lo, por petição, apresentada com 10 (dez) dias de antecedência, contados da data da audiência. $\$ 6^{\circ}$ Havendo litisconsórcio, o desinteresse na realização da audiência deve ser manifestado por todos os litisconsortes. $\mathbb{\$} 7^{\circ} \mathrm{A}$ audiência de conciliação ou de mediação pode realizar-se por meio eletrônico, nos termos da lei. $\mathbb{S} 8^{\circ} \mathrm{O}$ não comparecimento injustificado do autor ou do réu à audiência de conciliação é considerado ato atentatório à dignidade da justiça e será sancionado com multa de até dois por cento da vantagem econômica pretendida ou do valor da causa, revertida em favor da União ou do Estado. $\mathbb{S} 9^{\circ}$ As partes devem estar acompanhadas por seus advogados ou defensores públicos. $\mathbb{S} 10$. A parte poderá constituir representante, por meio de procuração específica, com poderes para negociar e transigir. $\$ 11$. A auto composição obtida será reduzida a termo e homologada por sentença. $\mathbb{1 2}$. A pauta das audiências de conciliação ou de mediação será organizada de modo a respeitar o intervalo mínimo de 20 (vinte) minutos entre o início de uma e o início da seguinte» [disponível em bttp://www.planalto.gov.br/ccivil_03/_ato2015-2018/2015/lei/l13105.btm (acesso em 16/05/2018)].

3 J. Knoepfler, «Médiation pénale, justice réparatrice, justice de próximité», em 
tende a restabelecer a ordem, em função da violação ao contrato social, e impõe um sofrimento proporcional à infração cometida. O adágio correspondente ao punitur quia peccatum est, significa punir porque uma falta foi cometida. A concepção reabilitadora tende, quanto a isto, a ressocializar o delinquente e a determinar suas necessidades a fim de ajudá-lo e trata-lo. O adágio consagrado é o punitur ne peccatur, punir para que ele não cometa nova infração penal.

A vítima é largamente negligenciada pelas duas concepções. De um lado há a canalização de um atávico desejo de vingança privada e sua transferência aos detentores do poder público pode revelá-la em si mesma, na medida em que leva a negar as feridas sofridas pela vítima, constituindo um vetor de vitimização secundária que amplifica o desejo de vingança que ela estava precisamente procurando apaziguar.

A teoria da justiça restaurativa ou reparadora, nascida nos anos setenta na América do Norte, procura aportar um corretivo às falhas do sistema criminal clássico. Uma das ideias fundadoras dessa corrente introduzidas pela criminologia de Nils Christie ${ }^{4}$ é que as principais partes interessadas foram desapropriadas do conflito e devem ser devolvidas à titularidade. Alguns anos depois, Howard Zehr publicou a obra: «Mudando De Lentes: Um Novo Foco para o Crime e a Justiça» pelo qual o autor revela que a justiça criminal, enxerga o crime através de lente essencialmente retributiva, ignorando a vítima e o autor do fato. Para Zehr, as vítimas de crimes têm muitas necessidades, muitas das quais nosso sistema de justiça criminal ignora. De fato, o sistema judiciário frequentemente aumenta a lesão. Os ofensores são menos ignorados por este sistema, mas suas necessidades reais — por responsabilidade, por fechamento, por cura — também são deixadas sem solução. Tais fracassos não são acidentais, mas são inerentes às próprias definições e suposições que governam nosso pensamento sobre crime e justiça. Zehr propõe a adoção de modelo restaurativo mais consistente com a experiência, com o passado e com a tradição bíblica. Parte da mudança na forma como o comportamento criminoso é observado: o crime deve ser entendido não apenas como violação à lei, mas também como lesão as vítimas e à comunidade, como uma ofensa entre duas pessoas e sua relação 5 .

V. Dittmann, A. Kuhn, R. MaAg e H. Wiprächtiger (eds.), Entre médiation et perpétuité, Zurich, Coire, 2002, p. 319.

${ }^{4}$ N. CHRISTIE, «Conflicts as Property», The British Journal of Criminology, Delinquency and Deviant Social Behavior, vol. 17 (1977), pp. 1 e ss.

${ }^{5}$ H. ZeHr, Changing Lenses: A New Focus for Crime and Justice, 3. ${ }^{a}$ ed., Scottsdale, Herald Press, 2005, pp. 32 e ss. 
Partindo da constatação que nas sociedades ocidentais o sistema penal clássico exclui as pessoas, portanto, os mais afetados pelo fenômeno criminal, a justiça restaurativa participa da vontade de lhes implicar adequadamente $^{6}$. Tanto quanto possível, as partes do conflito devem participar ativamente de sua resolução e mitigação de suas consequências.

A justiça restaurativa visa transformar a maneira como as sociedades contemporâneas apreendem e respondem ao fenômeno criminal e os problemas dele decorrentes. Os objetivos perseguidos são a reparação e o apaziguamento dos preconceitos que a vítima sofreu ainda que a responsabilização do delinquente tome em consideração a percepção de que seu comportamento não é aceitável e afetou os outros física, psicológica a materialmente.

Os princípios da justiça restaurativa se desenvolveram por diversas formas. Na América do Norte existem três abordagens relevantes: a mediação entre a vítima e o delinquente (Victm Offender Reconciliation Program, VORP), as conferências em família ou em comunidade (originárias de métodos práticos da Nova Zelândia e Austrália, Conferencing) e os círculos de sentença e reconciliação (Circles).

A corrente da justiça restaurativa conheceu progressiva e larga difusão através do mundo e em particular em toda a Europa onde se desenvolveu, de forma predominante, o modelo de mediação penal.

\section{CARACTERÍSTICAS DA MEDIAÇÃO PENAL}

Existem três definições de mediação em matéria penal. Para colocar em evidência as características de seu processo, se partirá de um dentre eles, a Recomendação núm. R (99) 19 sobre a mediação em matéria penal adotada em setembro de 1999 pelo Comitê de Ministros da Europa. A mediação em matéria penal se define como «qualquer processo para a vítima e o infrator participarem ativamente, se consentirem livremente, para a solução das dificuldades resultantes do crime, com a ajuda de um terceiro independente (mediador)». Dentre seus elementos característicos podemos destacar a confidencialidade absoluta das discussões encetadas no bojo da mediação, a liberdade das partes de aderirem a um processo de mediação e a qualificação adequada do mediador.

${ }^{6}$ J. L. SAWIN e H. ZEHR, «The Ideas of Engagement and Empowerment», em G. JoHnstoNE e D. W. VAn Ness (eds.), Handbook of Restorative Justice, Cullompton, Willan, 2007, p. 41. 
$\mathrm{Na}$ Espanha, o Conselho Geral do Poder Judiciário incluiu uma referência específica da mediação civil e penal como instrumento eficaz na resolução de conflitos: «Na mediação penal, vítima e infrator, através de um processo de diálogo e comunicação confidencial, conduzido e dirigido por um mediador imparcial, se reconhecem capacidade para participar em resolução...». O Código Penal Espanhol prevê as seguintes atenuantes genéricas: «a) o reconhecimento dos fatos; $b$ ) a reparação do dano causado; c) o perdão do ofendido». De outra parte, A Lei Espanhola do Estatuto da Vítima do Delito prevê conceito amplo de vítima, não apresentando qualquer restrição aos casos em que haja violência de gênero.

A mediação penal pressupõe em primeiro lugar a existência de um conflito. O conflito resulta do antagonismo posicional das partes e o procedimento de mediação tende a descontruir suas posições e lhes fazer evoluir, levando em conta os elementos subjacentes necessários à compreensão global da disputa e auxiliar as partes, de modo que, notadamente, os medos, preocupações, as percepções, os sentimentos, as emoções, os interesses, as necessidades e os valores.

Em segundo lugar, o conflito em questão tem a particularidade de ter nascido da prática de um crime. Tal circunstância induz necessariamente as necessidades e interesses particulares da vítima e do autor, os quais devem ser adequadamente tratados durante o procedimento de mediação.

Em seguida, a conduta do procedimento de mediação necessita a intervenção de um profissional especialmente formado para esta finalidade, imparcial e independente, a reunirem-se para gerenciar sua disputa e negociar um acordo com sua ajuda. O mediador aparece como um facilitar da comunicação entre as partes, que age sobre o processo de busca do acordo e não sobre o seu conteúdo. Através da escuta ativa, de reformulação e de maiêutica, ele ajuda progressivamente as partes a deslocarem a posição que apresentam em seus conflitos para identificarem seus interesses subjacentes e mudarem o paradigma comunicacional a fim de explorar as trilhas de solução às suas diferenças.

O único obstáculo no tocante da adoção do presente modelo ao procedimento de mediação é que o art. $30, \$ 4 .^{\circ}$ da Lei núm. 13.140, de 26 de junho de 2015 veda a sua confidencialidade caso constate a prática de crimes de ação penal pública. Entretanto, tal obstáculo pode ser facilmente dirimido com o prévio esclarecimento deste ponto às partes envolvidas no conflito ${ }^{7}$. Acresça-se que tal obstáculo já existe nos casos apresentados

${ }^{7}$ «Art. 30. Toda e qualquer informação relativa ao procedimento de mediação será 
diretamente à Vara de Família e Sucessões, sem que haja o benefício de que sejam trabalhados todos os aspectos apresentados no conflito.

\section{Objetivos da mediação penal}

Por intermédio desta técnica de gestão de conflitos, a infração é apreendida como direcionada as pessoas e suas relações e não simplesmente reduzida a uma transgressão a uma regra. Assim, a mediação penal é vista como «uma opção flexível, focada na resolução de problemas e no envolvimento das partes interessadas em complemento ou como alternativa ao processo penal tradicional» ${ }^{8}$.

$\mathrm{Na}$ perspectiva da vítima, o procedimento de mediação visa à satisfação do seu interesse em obter uma explicação, obter desculpas e uma reparação por parte do delinquente. Ele oferece a oportunidade de se fazer entender sua voz e de expressar sua vitimização e consequências, contribuindo para apaziguar sua cólera e facilitando seu restabelecimento a longo prazo.

Para as vítimas, especialmente em um contexto familiar, os impactos morais ou emocionais são tão ou mais importantes que as consequências materiais. Assim, consoante propugna Zeher, a vítima pode obter resposta as numerosas questões suscitadas pela infração onde ele é vítima, tornan-

confidencial em relação a terceiros, não podendo ser revelada sequer em processo arbitral ou judicial salvo se as partes expressamente decidirem de forma diversa ou quando sua divulgação for exigida por lei ou necessária para cumprimento de acordo obtido pela mediação. $\mathbb{S} 1 .^{\circ} \mathrm{O}$ dever de confidencialidade aplica-se ao mediador, às partes, a seus prepostos, advogados, assessores técnicos e a outras pessoas de sua confiança que tenham, direta ou indiretamente, participado do procedimento de mediação, alcançando: I. declaração, opinião, sugestão, promessa ou proposta formulada por uma parte à outra na busca de entendimento para o conflito; II. reconhecimento de fato por qualquer das partes no curso do procedimento de mediação; III. manifestação de aceitação de proposta de acordo apresentada pelo mediador; IV. documento preparado unicamente para os fins do procedimento de mediação. $\$ 2 .^{\circ}$ A prova apresentada em desacordo com o disposto neste artigo não será admitida em processo arbitral ou judicial. $\mathbb{S} 3 .^{\circ}$ Não está abrigada pela regra de confidencialidade a informação relativa à ocorrência de crime de ação pública. $\$ 4 .^{\circ} \mathrm{A}$ regra da confidencialidade não afasta o dever de as pessoas discriminadas no caput prestarem informações à administração tributária após o termo final da mediação, aplicando-se aos seus servidores a obrigação de manterem sigilo das informações compartilhadas nos termos do art. 198 da Lei núm. 5.172, de 25 de outubro de 1966 —Código Tributário Nacional (grifamos)— [disponível em http://www.planalto.gov.br/ccivil_03/_ato2015-2018/2015/lei/l13140.btm (acesso em 17.05.2018)].

${ }^{8}$ Recomendação núm. R (99) 19 adotada pelo Comitê de Ministros da Europa em 15 de setembro de 1999, Exposição de motivos, p. 14. 
do-o capaz de compreender os fatos e porque ele foi alvo, porque ele assim reagiu dessa forma ao fato e como ele reagirá no futuro e porque ele reagiu ao fato depois da infração. A possibilidade de reencontrar o autor do fato permite a vítima obter uma certa quietude e atenuar o sentimento de insegurança gerado pela infração, tornando a vítima capaz de receber um pedido de desculpas, a expressão de um arrependimento sincero. Isto contribui para a diminuição de seu desejo de vingança.

A participação como verdadeiro ator do processo de resolução do conflito restitui a vítima o sentimento de dono/condutor da situação que lhe foi tolhida com o cometimento da infração, a revitimização faz com que ele perceba uma perda do poder de controle da situação. Relegada ao lugar de objeto da infração cometida, ainda que haja a responsabilidade do autor pelo crime pelo direito penal clássico, a vítima necessita de um papel ativo a fim de devolver a ela o sentimento de controle da situação que lhe foi retirado.

Enfim, a vítima deve receber compensação pelos danos sofridos e, em particular das perdas financeiras e materiais advindas com a infração. A primeira compensação a ser obtida é a de natureza pecuniária. É interessante revelar que a vítima busca mais do que uma compensação material, podendo esta assumir a feição material ou simbólica (pagamento de importância a vítima, prestação de serviços para a vítima, prestação de serviços em benefício da comunidade ou a um objetivo humanitário, publicação de uma retratação, etc.).

Para o autor da infração a mediação tende a reforçar o seu senso de responsabilidade e a the oferecer oportunidades concretas de se emendar, tendo que enfrentar diretamente a consequência do crime praticado e a dor causada à vítima. Pelo seu papel ativo e não apenas defensivo, o autor não é mais marginalizado enquanto membro da sociedade. Pelo reencontro com a vítima o autor pode constatar as consequências humanas de seu comportamento e a considerar sua vítima como uma pessoa e não como um simples alvo ou um objeto. Pela personalização da vítima, o autor toma consciência concreta das lesões causadas (físicas, psíquicas ou materiais).

\section{Objeções à aplicação da mediação penal em contexto de violência doméstica e familiar contra a mulher}

A doutrina majoritária é contrária a aplicação da mediação penal aos casos de violência de gênero por entender que: existe desequilíbrio 
de poder entre a vítima e o agressor; princípio da legalidade da ação penal, sendo discutível que o Estado possa renunciar ao jus puniendi ${ }^{9}$, sua aplicação é proibida pelo Manual de Legislação de Violência Contra a Mulher, Nova York, 2010, p. 40, cujo ponto 3.9.1 se recomenda «Proibir explicitamente a mediação em todos os casos de violência contra a mulher, tanto antes como durante os procedimentos judiciais»; permitir a mediação penal seria um retrocesso na luta contra a violência de gênero; no Brasil a Lei Maria da Penha veda a aplicação de institutos da Lei núm. 9.099/95, tais como a transação penal e a suspensão condicional do processo.

\section{Da possibilidade da mediação penal}

A objeção atinente ao desequilíbrio de poder entre as partes encontra na mediação técnicas adequadas para evitar a revitimização da mulher e muitas vezes revela o desconhecimento do procedimento de mediação e suas técnicas, uma vez que o mediador e as partes podem optar pelo realização de audiências exclusivamente privadas (caucus), sendo revelado a outra parte apenas o que for expressamente acordado na sessão de mediação, mesmo no caso de prática de crime de ação penal pública, uma vez que este dever de não confidencialidade deve ser interpretado como referente aos órgãos de persecução penal. Aliás, em se tratando de violência de gênero, o delito cometido em regra não é desconhecido pela vítima e, nos crimes praticados sem violência física, não se pode negar ao autor do fato o direito de tentar celebrar, com participação direta do «parquet» nos crimes de ação penal pública e participação posterior nos crimes de ação penal privada, do direito de obter uma atenuação de pena pela confissão, uma valoração adequada das consequências do crime para a vítima ao aplicar a pena ou mesmo um acordo de não persecução penal (nos delitos praticados sem violência física), confessando integralmente o delito e reparando o dano causado. Assim, não há ofensa ao princípio da legalidade, mas aplicação sistemática da legislação penal.

A intervenção do Ministério Público na mediação no caso de acordo entre as partes que verse sobre direito indisponível, porém transigível é obrigatória por expressa disposição legal.

${ }^{9}$ M. A. Renedo Arenal, «¿Mediación penal en violencia de género? No, gracias», Revista Europea de Derechos Fundamentales, núm. 23 (2014), pp. 177-198, disponível em bttps://dialnet.unirioja.es/descarga/articulo/4945878.pdf(acesso em 14.05.2018). 


\section{CONCLUSÃO}

A violência de gênero comporta tratamento especializado do conflito familiar e/ou relacional existente. A inclusão dos verdadeiros atores do conflito em ambiente de gerenciamento de conflitos permite a manutenção dos laços existentes, mediante a transformação da comunicação disfuncional e cessação de situações de violência.

O Estado ao intervir em casos de violência de gênero substitui seus protagonistas, mas não tem o poder em ambiente representativo e ficcional do ocorrido de transformá-lo.

Não se pode negar às partes o direito de serem escutadas, ainda que separadamente (caucus) por especialista em gerenciamento de conflitos, bem como que subsequente julgamento abarque todas as consequências advindas de uma infração penal, sejam estas cíveis ou criminais, uma vez que ausente em nosso ordenamento jurídico a possibilidade de oferecimento pelo parquet de acordo de imposição negociada de pena. Nos crimes de ação penal privada e naqueles condicionados à representação da vítima, a disponibilização da mediação penal favorece a obtenção de formas criativas de reparação do dano. Cumpre mencionar que, a faculdade conferida à vítima em propor a queixa-crime ou oferecer a representação ou desta se retratar nos crimes de ação penal pública condicionada até o oferecimento da denúncia já se encontram disponibilizados no ordenamento jurídico brasileiro. Nos crimes de ação penal pública incondicionada não se pode negar às partes o direito de serem escutadas, com a consequente reparação do dano à vítima e correlata atenuação da pena a ser imposta ao infrator, ou mesmo a correta valoração da pena a ser imposta pelo magistrado dentro dos parâmetros legais estabelecidos no tipo penal secundário nos casos de ação penal pública incondicionada.

O tratamento integrado do conflito no Brasil está expressamente estabelecido no art. 13 da Lei 11.340/06 que estabelece como regra para processo, julgamento e execução o juiz e promotor do fato (competência cumulativa). A mediação se encontra disciplinada em leis específicas e posteriores, razão pela qual é direito de as partes em situação de violência doméstica e familiar optarem ou não pelo uso desta técnica. Além disso, a vítima tem direito que todos os aspectos do conflito (cíveis e criminais) sejam apreciados pelo juiz e promotor do fato e, a ausência de sua apreciação em ambiente especializado constitui ato atentatório à sua dignidade. 


\section{BIBLIOGRAFIA}

Christie, N.: «Conflicts as Property», The British Journal of Criminology, Delinquency and Deviant Social Behavior, vol. 17 (1977), pp. 1-26.

KNOEPfler, J.: «Médiation pénale, justice réparatrice, justice de próximité», em V. Dittmann, A. Kuhn, R. MaAg e H. Wiprächtiger (eds.), Entre médiation et perpétuité, Zurich, Coire, 2002.

Renedo Arenal, M. A.: «¿Mediación penal en violencia de género? No, gracias», Revista Europea de Derechos Fundamentales, núm. 23 (2014), pp. 177-198, disponível em bttps://dialnet.unirioja.es/descarga/articulo/4945878.pdf (acesso em 14.05.2018).

Santos, C. L. dos: Mediação para o Divórcio, tese de doutorado defendida na Faculdade de Direito da Universidade de São Paulo em 2003.

SAwIN, J. L., e ZeHr, H.: «The Ideas of Engagement and Empowerment», em G. Johnstone e D. W. Van Ness (eds.), Handbook of Restorative Justice, Cullompton, Willan, 2007, p. 41.

ZeHr, H.: Changing Lenses: A New Focus for Crime and Justice, 3. ${ }^{a}$ ed, Scottsdale, Herald Press, 2005. 